\title{
VRAE RONDOM DIE TRADISIONELE BENA- DERING VAN DIE AFRIKAANSE TAALBEWE- GINGS
}

\author{
L.T. du Plessis
}

Dept. Afrikaans en .Nederlands, UOVS

\section{ABSTRACT}

In this article the traditional approach to the history of the Afrikaans language movements, the so-called "Eerste Afrikaanse Taalbeweging" and "Tweede Afrikaanse Taalbeweging" is criticized, more specifically the traditional evaluation of the relation between the "Genootskap van Regle Afrikaners" (GRA) and the first language movement. Under discussion is a new concept of what a language movement is, namely that a language movement is determined mainly by a political and/or a religious force. In other words, a politically dominant group of people would make use of the sentimental power of their language the mobilize themselves into a political force. Once they have taken over the power of government their language will most likely receive official status. With this "criterion" in mind, the history of the Afrikaans language movements can be analyzed against the background of five different language movements, i.e. the "Oosgrenstaalbeweging" (1860), the "Maleierafrikaanse taalbeweging" (1866), the "Byvbelvertalingsbeweing" (1872), the "Afrikanerbondbeweging" (1880) and the only successful one, the "na-oorlogse taalbeweging" (1914). The latler succeeded because of the immense success of $A$ frikaner nationalist politics, not because of the beauty or so-called "wonder" of the Afrikaans language, as is often believed. The GRA was no language movement at all, but part of the "Bybelvertalingsbeweging". The motive behind this language movement was a religious one: 10 convert the poor Afrikaansspeaking population of the Cape Colony to Christianity. An Afrikaans Bible became a bare essential for this mission and thus explains the efforts of Pannevis and later the GRA to translate the Bible into Afrikaans. The whole effort was not to promote Afrikaans as a language at all. Some other facts concerning the erection of the GRA are put into perspective, for instance: the dale 14 August 1875, considered as the date upon which the GRA was formed, has been proved false. A new date has been decided upon, which is more accurate, namely 25 September of the same year.

The aim of this article is not so much to degrade the special efforts of the GRA or the so-called first Afrikaans language movement, as to put this history in a new perspective. It is of utmost importance for the future of the Afriknans language that its people will treat and maintain it in an objective way. Presentlv this matler is being dealt with by a minority group of Afrikaners who consider the Afrikaans language as their exclusive right. All maintenance efforts are thus limited 10 a rather small portion of the

48(4)1983 


\section{Vrae rondom}

Afrikaans-speaking community. It is this same group that also over-estimates and idealizes the contribution of the GRA and the "Eerste Afrikaanse Taalbeweging" in the development of Afrikaans as a standard language of the RSA. By looking back into history in a less prejudiced way this maintenance effort could become the concern of the Afrikaans community as a whole.

\section{VOORAF}

Verlede jaar is die bekendstelling van sekere bevindings wat in die verhandeling, 'n Kritiese beskouing van die identifikasie van die Afrikaanse taalbewegings en hulle funksies (Du Plessis 1983), gemaak is nie orals instemmend aanvaar nie. Die uitspraak dat die GRA nie die eerste Afrikaanse taalbeweging was nie en bowenal nie ' $n$ taalbeweging was nie is onder andere as 'n "vreemde redenasie" bestempel. Verder word die siening dat 'n taalbeweging nie wentel om die uitbouing van ' $n$ taal nie, maar primêr 'n politicke oogmerk het, soos volg opgesom:

"Hoe 'n mens so 'n strooipop kan staanmaak sodat dit des te makliker omgestamp kan word, gaan die verstand eflens te bowe" (Die Burger, 21/5/83). (Uit hierdie tipe reaksie blyk duidelik dat 'n mens versigtig moet omgaan met enige poging om 'n nuwe perspekt ief te gee op die volksverlede.) Dit sou moontlik die moeite loon om meer duidelikheid te gee oor sommige van die uitsprake wat gemaak is.

Die doel met hierdie artikel is derhalwe om (a) nuwe kriteria daar te stel vir 'n taalbeweging, (b) kortliks aan te dui waarin die tradisionele benadering tot die Afrikaanse taalbewegings te kort skiet, (c) volgens dié kriteria 'n alternatiewe benadering tot die Afrikaanse taalbewegings uiteen te sit, cn (d) die GRA se rol binne dié nuwe perspektief te evalueer.

\section{KRITERIUM VIR 'N TAALBEWEGING}

Steyn het in sy nou byna klassieke werk, Tuiste in eie taal, vir die eerste keer in Afrikaans gevolgtrekkings gemaak oor die "kenmerke" van 'n taalbeweging en die uitkomste hiervan toegepas op die Afrikaanse taalbewegings. 'n Belangrike reaksie hierop is die van Van Rensburg 1981 wat aantoon dat dié uiteensetting ruimte laat vir' $n$ siening waarin die $\mathbf{k l e m}$ anders val as die aanvaarde benadering van die Afrikaanse taalbewegings. Buiten die feit dat 'n taalbeweging volgens Steyn 1980 gekenmerk word deur drie definitiewe fases, naamlik 'n bewusmakings-, stryd-en handhaaffase, blyk volgens Van Rensburg (1981) dat dic die dryfveer daaragter van kardinale belang behoort te wees. Waaraan word die relatiewe sukses van die Vlaamse 


\section{L.T. du Plessis}

taalbeweging byvoorbeeld tocgeskryl? Hoekom "misluk" die lerse taalbeweging? Waarom het die sogenaamde Eerste Afrikaanse taalbeweging misluk, terwyl die sogenaamde Tweede Afrikaanse taalbeweging geslaag het?

Steyn maak o.a. die volgende opmerkings oor taalbewegings: "Politieke mag is noodsaaklik vir die vordering in 'n taalbeweging' (Steyn, 1980: 148) en "... die geskiedenis leer dat 'n taalbeweging nie kan slaag sonder'n stryd aan die politieke ekonomiese en kulturele 'front' nie" (a.w. : 90). Hierdie opmerkings illustreer die noue verbondenheid Iussen taal en politiek, of: die verband tussen politieke sukses en taalsukses. Sy volgende opmerking illustreer dit ook: "Solank die Provencaalse beweging suiwer'n taalbeweging was, kon dit nie groei nie" (a.w. : 89). Uit bostaande uitsprake blyk dit dus dat taal nie sonder meer uitgesonder kan word as die dryfveer agter 'n taalbeweging nie, maar dat die dryfveer (gewoonlik) politiek is. Dit is daarom belangrik om die verband tussen taal en 'n laalbeweging vanuit dié perspektief te benader: Taal is ' $n$ middel tot die doel, nie die doel op sigself nie.'

'n Suksesvolle taalbeweging het die vestiging van 'n taal tot gevolg. 'n Nie-standaardtaal waarvan die sprekers geen politieke mag besit nie word nie eensklaps as standaardtaal of ampstaal van 'n land erken nie. Dit is die sukses van die politieke stryd - wat die strydfase van 'n taalbeweging verteenwoordig - wat daartoe lei. Die politieke stryd is die werklike "taalstryd" wat die ophefling van die taal tot gevolg het. Haugen (1981 : 100) illustreer dić sonderlinge samehang tussen taal en politick: "If there is anything we can learn from the Scandinavian experience, it is the importance of political power in establishing languages".

'n Ander belangrike dryfveer agter'n taalbeweging is godsdiens. Tussen die Protestantisme en die bevordering van Duits het 'n noue samehang bestaan (vgl. Steyn, 1980 : 44). Luther se Bybeltaal het toonaangewend geword en ander plaaslike skryftale heeltemal verdring (Malherbe, s.j. : 74). Die Hervorming het ook die volkstale laat opleef as skryftale terwyl die .hernieude belangstclling van etlike nasionale letterkundes, soos diè van Goties en party Slawiese tale, uitsluitlik te danke is aan die godsdiens van die Hervorming (Steyn, 1980:44). Wallies weer is bevoordeel deur die Metodistiese herlewing van die $18 d e$ ecu (a.w. : 44).

\footnotetext{
1 Pietersen, 1976 : 147.152 ("Taalstrijd is sociale strijd") lê veel klem op taal " ... als machtsinstrument" en verwys onder meer na die taalstryd in Friesland, " "sociaal-politieke" stryd, waar Fries as die middel tot 'n doel gebruik word
} 


\section{Vrae rondom}

Die vestiging van Hebrecus as taal van die verenigde Joodse volk dien weer as illustrasie daarvan dat beide godsdiens én politiek dryfvere kan wees. (Vgl. Steyn, 1980 : $70 / 4$ en Du Plessis 1983 : 7/9.) Politiek-geïnspireerde taalbewegings kom egter meer dikwels voor en dit lyk ook asof politiek 'n sterker dryfveer is as godsdiens (vgl. Du Plessis, $1983: 7$ ).

Die begrip taalstryd word volgens die voorafgaande argumente gekoppel aan dié fase waarin taal uitgebuit word in belang van 'n politick en/of godsdienstige doel. ${ }^{2}$ Sodra dié ideaal verwesenlik word, het die taal sy doel gedien. Die taalsiryd is dan verby. Hierna behoort die taal gekonsolideer te word. Begrippe soos taalhandhawing en laalbevordering hoort tuis by die handhaaffase van 'n taalbeweging. Aan die spits van so 'n veldtog staan nou nie meer politici nie, maar taalhandhawers of taalbeplanners.

\section{PROBLEME MET DIE TRADISIONELE BENADERING}

Die tradisionele siening van die Afrikaanse taalbewegings lewer in die lig van die voorafgaande die volgende probleme op:

- Daar word geen bevredigende verklaring gegee vir die sukses van die sogenaamde Tweede en die mislukking van die sogenaamde Eerste Taalbeweging nie.

- Godsdiens, politiek én taal word tegelyk as dryfveer agter die sogenaamde Eerste Taalbeweging genoem.

- Die sogenaamde Eerste Taalbeweging wentel skynbaar om 'n genootskap, die GRA, wat afgestem was op die bevordering van Afrikaans en dus 'n handhaaf-aksie was in 'n tyd toe Afrikaans nog nie as parlementêre taal erken was nie.

- 'n Bevredigende definisie van 'n taalbeweging word nie gegee nie. Die bestaande siening is blykbaar gebaseer op dié van S.J. du Toit, wat nie toetsbare maatstawwe vir 'n taalbeweging opgestel het nie.

- Die huidige (lewendige) gesprek rondom die toekoms van Afrikaans word bestempel as 'n sogenaamde nuwe taalbeweging.

2 Steyn 1980 gebruik in baie gevalle laalstryd en laalbeweging as sinonieme waardeur die politieke aard van die strydlase nie duidelik blyk nie. 


\section{L.T. du Plessis}

- Die klem by die tradisionele benadering val deurgaans op die "wonder" van die Afrikaanse taal waardeur die geskiedenis van die opkoms van Afrikaans as ampstaal met 'n oormaat van taalsentiment vertroebel word.

- Derhalwe word die sukses van die Tweede Afrikaanse Taalbeweging nie aan die politieke sukses van die Afrikaner van die 20-erjare toegeskryf nie, maar aan die feit dat Afrikaans die stryd teen Engels gewen het.

- Ander Afrikaanse taalbewegings word nie in aanmerking geneem nie.

Uiteraard kan hierdie probleme nie volledig binne die bestek van dié artikel behandel word nie. Binne die raamwerk van die reeds gestelde doel witte sal sekere aspekte van dié problematiek egter wel aangesny word.

\section{4. 'N NUWE INDELING VAN DIE AFRIKAANSE TAALBEWE- GINGS}

Met die kriterium dat ' $n$ taalbeweging primèr wentel rondom ' $n$ aksieveldtog waar die taal van 'n veronregte groep uitgebuit word in belang van 'n politieke en/of godsdienstige ideaal, kan 'n nuwe identifikasie en indeling van die Afrikaanse taalbewegings gemaak word. In die vorige eeu is Afrikaans by verskeie geleenthede uitgebuit om politieke en godsdienstige doelwitte te bereik. In terme hiervan was daar dus sprake van meer as een Afrikaanse taalbeweging. Anders as wat tradisioneel die geval is, word die volgende vooroorlogse (vóór die Tweede Vryheidsoorlog) taalbewegings onderskei: $)^{3}$

- die Oosgrenstaalbeweging wat wentel om die afskeidingsbeweging aan die Oosgrens in die 1860-erjare waarin Afrikaans onder leiding van Meurant gebruik is om afskeidingspolitiek onder die Afrikaanssprekende gemeenskap aldaar te propageer (dus die eintlike éérste Afrikaanse taalbeweging);

- die Maleier-Afrikaanse taalheweging vanafongeveer 1862 waarin Afrikaans deur Abu Bakr en ander Moslemleiers gebruik is om die Islam onder die Maleiergemeenskap te bevorder;

3 VRl. Du Plessis (1 983) vir vollediger besonderhede 


\section{Vrae rondom}

- die Bybelverlalingsbeweging wat vanaf 1872 onder leiding van Pannevis se inisiatief begin is met as doel die kerstening en beskawing van die minderbevoorregte Afrikaanssprekendes (aanvanklik die Bruinmense maar later ook die Blankes) deur middel van 'n Afrikaanse Bybel. Die stigting van die GRA was 'n belangrike mylpaal van dié taalbeweging;

- die Afrikanerbondbeweging vanaf 1880 onder leiding van S.J. du Toit wat hom ten doel gestel het om die Afrikaner polities op te hef. Afrikaans was die belangrikste propagandamiddel van dié beweging.

Nie een van die bogemelde taalbewegings het geslaag nie. Die enigste suksesvolle Afrikaanse taalbeweging was

- die na-oorlogse taalbeweging. Dié beweging wentel om die opkoms en groei van Afrikanernasionalisme met die stigting en groei van die Nasionale Party vanaf 1914.

In 1924 het die Afrikaner vir die eerste keer politieke beheer in Suid-Afrika verkry. Net die volgende jaar het sy taal, die belangrikste middel waarmee die Afrikanernasionale band sedert 1914 gesmee is, 'n mede-ampstaal van Suid-Afrika geword (naas Engels en Nederlands). Hier het die na-oorlogse of vyfde Afrikaanse taalbeweging nie geëindig nie. Slegs die suksesvolle taalstryd is toe beëindig. Die handhaaffase van dié taalbeweging het strenggesproke toe begin - die fase waarin Afrikaans hom tewens nog bevind.

Met die nuwe indeling word die gegewens oor die sogenaamde Eerste Taalbeweging in 'n ander lig gestel. Veral die GRA word binne 'n veel minder beklemtoonde perspektief geplaas.

\section{DIE GRA BINNE DIE NUWE INDELING - PERSPEKTIEWE EN IMPLIKASIES}

Tradisioneel word die geskiedenis van die sogenaamde Ecrste Afrikaanse Taalbeweging gekoppel aan die vroegste pogings om die Bybel in Afrikaans te vertaal, die oprigting en werksaamhede van die GRA, die sukses wat $D i$ Patriot behaal het, die oprigting van die Afrikanerbond en die talryke publikasies wat verskyn het onder die vaandel van die GRA. In dieselfde verband word die oprigting van 'n Afrikaanse skool by Daljosafat en van die eerste Afrikaanse besighede genoem. 


\section{L.T. du Plessis}

(Vgl. o.a. Nienaber en Nienaber, 1941, Pienaar, 1943 en 'n baie resente werk, Kannemeyer, 1983, vir'n uiteensetting van die tradisionele benadering. ${ }^{4}$

Soos hieruit blyk, val die klem wat die geskiedskrywing betrel veral op die GRA. Daarvan getuig ook die sentimentele aanhang van die GRA soos veral blyk uit die oprigting van 'n taalmonument in die Paarl, asook die waarde wat geheg word aan 14 Augustus - die gewaande stigtingsdatum van die GRA op 14 Augustus 1875. Dat die werksaamhede van die GRA belangrik geag word, word beklemtoon deur die feit dat 'n taalmuseum in die Paarl opgerig is in die huis van 'n stigterslid, Gideon Malherbe, en die huidige beplanning van 'n taalroete deur die Paarlvallei. Uiteraard sal enige kritiek teen die bestaande beskouing nie verwelkom word deur diegene wat opgaan in die tradisionele verheerliking van die bydrae wat die GRA tot Afrikaans gemaak het en nie van ander standpunte kennis neem nie.

Daar is gevare verbonde aan so 'n GRA-geaksentueerde benadering tot die Afrikaanse taalbewegings. Die geskiedenis van die ontwikkeling van Afrikaans as kultuurtaal word onvolledig uitgebeeld en ander belangrike gebeure wore geïgnoreer. Die ampstaalwording van Afrikaans word nie in 'n objektiewe lig gestel nie. Slegs 'n klein groepie mense (die GRA en sy navolgers) word uitgesonder as "taalhelde" en hulle relatiewe taalprestasies word opgeblaas tot 'n kragvertoon vir Afrikaans, sonder dat byvoorbeeld hulle motiewe met die bevordering van die taal ooit bevraagteken word. Gevolglik het die geskiedenis van die ontwikkeling van Afrikaans as kultuurtaal 'n redelik eksklusiewe kleur gekry, enige poging om die GRA se rol in perspektief te stel, kan feitlik as heiligskennis beskou word. So stewig is die tradisionele idees gevestig.

Die GRA was egter nie op sigsell'n taalbeweging nie, maar'n uitvloeisel van pannevis se Bybelvertalingsveldtog. Hoewel die GRA gestig is met die uitsluitlike doel om die weg te berei vir'n Afrikaanse Bybelvertaling het sy werksaamhede uiteindelik veroorsaak dat juis dié ideaal nooit verwesenlik is nie! (Eers in 1890, 15 jaar ná sy stigting, en 12 jaar na sy ontbinding ${ }^{5}$ is ernstig begin werk aan 'n Bybelvertaling. Die eerste vertaalde Bybelboek verskyn eers in 1893, 18 jaar nadat die GRA gestig is.) Hierbenewens het die vorm van Afrikaans wat deur die GRA bestendig is 'n Kaapse kleur gehad,

\footnotetext{
1 Kannemeyer wyk in hierdie Iweede uilgawe van sy blokboek oor die Afrikaanse taalbeweging slegs in 'n geringe mate af van die tradigionele siening, maar neem ongelukkig nie kennis van o.a. Steyn (1980) se insigte oor die onderwerp nie.

3 Dic GRA het in 1878 amptelik ontbind (vgl. Du Plessis, 1983: 124/5).
} 


\section{Vrae rondom}

soos blyk uit die GRA-geskrifte. Die bolandse vorm van Afrikaans was onaanvaarbaar vir die binnelandse Afrikaanssprekende en kan nie beskou word as die basis van die taal wat in $\mathbf{1 9 2 5}$ medeampstaalstatus verkry het nie (vgl. Ponelis, 1983).

Is die GRA gestig met 'n godsdienstige doel voor oë, om Afrikaans te bevorder, of om die Afrikaner polities op te hef?

S.J. du Toit het self aangevoer dat die GRA gestig is om die Bybel in Afrikaans te vertaal (vgl. Du Toit, $1909: 66$ ). Dit is deur Totius bevestig (vgl. Du Toit, 1917 : 66). Volgens Nienaber (1934: 15) het die sogenaamde Eerste Taalbeweging “ ... sy geboorte direk te danke aan die begcerte om die Bybel in Afrikaans oor te sit". Geskiedkundig is dit bekend dat Pannevis die veldtog om 'n Afrikaanse Bybel geinisieer het, wat beteken dat die stigting van die GRA 'n uitvloeisel van dié veldtog was. Die ideaal om die Afrikaanssprekende te kersten deur middel van 'n Afrikaanse Bybel het vergestalting gevind in die oprigting van die GRA. Godsdiens was dus die dryfveer hieragter. Daarom die afleiding dat hier sprake was van 'n afsonderlike taalbewcging, t.w. die Bybelvertalingsbeweging.

Die "doel" van die GRA was egter: "Om te staan vir ons Taal, ons Nasie en ons Land" (Du Toit, 1909 : 67), en bo-aan die GRA-wapen pryk die woorde: "Verenigde Suid-Afrika". Die mondstuk van die GRA, Di Patriol, het hom vanaf 1877 begin toespits op politieke kwessies en die taalsaak agterweë gelaat (De Waal, 1932: 11). In 1879 publiseer Du Toit in dieselfde blad die konsep van die Afrikanerbond, 'n politieke liggaam met die strewe om die Afrikaner polities op te hef. Sou die dryfveer agter die sogenaamde Eerste taalbeweging dus van godsdiens na politiek verskuif het? Of was beide ter sprake?

Die feit dat die saak van die Bybelvertaling eers weer in 1884 ter sprake gekom het, dit wil sê amper 10 jaar na die stigting van die GRA, skakel eersgenoemde moont likheid uit. Ook het dié organisasie hom nie bewys as'n liggaam wat die Afrikanervolk polities kon saamsnoer nie (vgl. Van Rensburg, 1981 : 53). Historici en taalhistorici het egter not altyd die rol van die GRA in die politieke ontwaking van die Afrikaner belangrik geag, waardeur die sogenaamde Eerste Taalbeweging 'n politieke dimensie sou vcrkry het. Die GRA ontbind egter juis as gevolg van 'n gebrek aan politieke dimensie. Du Toit (1909: 67) skryf in sy laaste jaarverslag (1878) dat die GRA veral een tekort koming openbaar het, naamlik "gesag". Hy skryf dat leiers van die GRA geen invloed gehad het op die politieke lewe nie. Verder erken 


\section{L.T. du Piessie}

hy dat die GRA nooit 'n politieke ideaal sou bereik nie, “... daartoe was dit (die GRA - LTdP) te beperk tot die Afrikaanse taal”' (Du Toit, $1882: 2$ ).

Uit bogenoemde getuienis blyk dat die GRA as godsdienstig-kulturele organisasie nie geskik was om die volk polities saam te snoer nie. Met die oprigting van die Afrikanerbond in 1880 is dié ideaal egter verwesenlik. Interessant genoeg beleef Di Patriot (die Afrikanerbond se erkende lyfblad) juis in hierdie tydperk 'n florieryke era, met politiek as dryfveer (vgl. Du Toit, 1917: 153/5). Die taalbeweging wat hierom ontstaan het, word as die Afrikanerbondbeweging geïdentifiseer.

'n Derde moontlikheid kom ter sprake, naamlik dat die GRA suiwer 'n taaldoelwit nagestreef het. Volgens die voorafgaande bespreking is dit duidelik dat die GRA nie politiekgeïnspireerd was of 'n politieke propagandaliggaam was nie, maar deel was van die Bybelvertalingsbeweging. Kyk mens weer na die afloop van dié taalbeweging, blyk dit dat die godsdienstige ideaal ná die stigting van die GRA ietwat op die agtergrond geskuif het. In plaas daarvan het die bevordering van Afrikaans as sodanig voorop kom staan: Uit die notules van die GRA, asook uit verskeie van die publikasies wat deur dié genootskap gepubliseer is, blyk dat 'n daadwerklike poging aangewend is om Afrikaans te bevorder, eerder as om daadwerklik te werk aan 'n Afrikaanse vertaling van die Bybel. Dié nuwe aksent kan soos volg verklaar word: As voorwaarde vir die vertaling van die Bybel in Afrikaans het die Britse en Buitelandse Bybelgenootskap (hierna verkort tot BBBG) sekere eise gestel. Met die stigting van die GRA kon hulle nie aan dié eise voldoen nie, bv. dat Afrikaans as onderrig- en skryftaal gebruik moes word, dat die potensiële vertalers vertalingsbevoeg sou wees en dat daar proefvertalings, voorsien moes word (vgl. Du Toit, $1909: 61 / 2$ ). Op hulle prioriteitslys was die opstel van spelreëls vir Afrikaans en die saamstel van 'n Afrikaanse woordeboek aangeteken - 'n vroeë poging dus om Afrikaans te reglementeer. ('n Poging om te voldoen aan die eise wat die BBBG gestel het?) Hoe dit ook al sy, taal is deur die GRA voorop gestel. Die middel tot die doel het die doel self geword. Daarvan sê Du Toit "dat ons geen besondere verwagting het van 'n genootskap, enkel vir di taal ni ... omdat so 'n poging voor 'n paar jaar geheel misluk is" (Du Toit, 1917 : 147). Later verdedig Du Toit hierdie siening en beklemtoon by hernuwing sy beswaar teen 'n "blotetaal beweging" (a.w. : 147). Dit is die rede waarom hy 'n organisasie op die been gebring wat 'n politieke doel voor oë gehad het, naamlik die Afrikanerbond (Du Plessis, 1983 : 138/9).

Die dryfveer agter die stigting van die GRA was dus in die eerste plek 


\section{Vrae rondom}

godsdienstig van aard. As gevolg van die hoě eise wat die BBBG aan die GRA-manne gestel het, het die klem verskuif na taalbevordering wat uiteindelik tot die mislukking van die Bybelvertalingsbeweging bygedra het.

- T.o.v. die stigtingsdalum

Hoewel die stigtingsdatum van die GRA op sigself nie van veel belang vir hierdie artikel is nie, word kortliks daarop gewys dat die Genootskap van Regte Afrikaners gestig is op 25 September 1875, nie op 14 Augustus 1875 nie. Indien Du Toit (1909) se weergawe van die gebeure wat aanleiding gegee het tot die stigting van die GRA noukeurig bestudeer word, blyk die chronologie daarvan problematies te wees. (Kyk Du Plessis, 1983 : 111-124 vir die volledige bespreking hiervan, asook Du Plessis, 1983a vir 'n herindeling van die gebeure rondom die eerste Afrikaanse Bybelvertaling.)

Daar behoort gewaak te word teen die oorbeklemtoning van die datum 14 Augustus en veral teen die sentimentalisering daarvan. Groter bakens staan op die pad wat Afrikaans geloop het as wat diegene wat met soveel fanatisme dié datum aanhang, bereid is om toe te gee.

'n Mens is geneig om na aanleiding van die voorafgaande die vraag te stel of die GRA hoegenaamd ' $n$ rol gespeel het in die ontwikkeling van Afrikaans tot standaardtaal. Natuurlik word die aandeel van die GRA nie misken nie. Die vermoede bestaan egter dat S.J. du Toit in sy geskiedskrywing die GRA se aandele oorbeklemtoon het en dat latere skrywers hom op allerlei wyses nagevolg en selfs op hom uitgebrei het, sonder om weer oorspronklike navorsing te doen. In dié opsig is die tradisionele benadering 'n erflating van Du Toit. Verskeie argumente kan aangevoer word om aan te toon dat die GRA se aandeel in die ontwikkeling van Afrikaans tot standaardtaal oorbeklemtoon word.

\section{- T.o.v. die reglementering van Afrikaans}

Die spelreëls wat Du Toit opgestel het en wat deur die GRA nagevolg is, is deur die Akademie geïgnoreer. Dié liggaam se Taalkommissie het hulle aangesluit by die VNS-stelsel - selfs vandag nog word die GRA-tradisie deur die Taalkommissie oor die hoof gesien.

Die woordeboek wat die GRA saamgestel het, vind hoogstens 'n nut in die WAT-kantoor en by andere vanuit 'n kuriositeitsoogpunt. 


\section{L.T. du Plessis}

Du Toit se uiteindelike Bybelvertalings het nooit amptelike erkenning ontvang in die Afrikaanse kerke nie. Die 1933-vertalers het nie voortgebou op sy arbeid nie. Hulle het 'n geheel nuwe vertalingsbeleid daargestel en hulle vertaling gebaseer op die Statevertaling (vgl. Du Plessis, 1983a).

\section{- T.o.v. die erkenning van Afrikaans}

Die GRA het in sy driejarige bestaan feitlik net negatiewe reaksie ontlok en het as gevolg van sy politieke onmag in geen stadium in die posisie verkeer om Afrikaans as parlementêre taal erken te kry nic.

Daarbenewens blyk duidelik uit die geskrifte van die GRA dat hy 'n Bolandse vorm van Afrikaans probeer reglementeer het - ongeveer die vorm van Afrikaans wat vandag nog in die Boland gepraat word. In 1925 het die meer noordelike vorm van Afrikaans ' $n$ mede-ampstaal in SuidAfrika geword, nie die Afrikaans wat deur die GRA bevorder is nie. (Vgl. Ponelis, 1983, se uiteensetting van standaard-Afrikaans.)

- T.o.v. die ATG en die ATV

Dat die GRA-manne se denkwyse 'n invloed gehad het op die stigters van die Afrikaanse Taalgenootskap (ATG) en Afrikaanse Taalvereniging (ATV) aan die begin van die 20ste eeu, word nie betwyfel nie. Tewens, die ATG se doelstellings toon verrassende ooreenkomste met dié van die GRA (Du Plessis, $1983: 176)$. Die vraag is egter watter aandeel dié na-oorlogse taalorganisasies gehad het in die erkenning van Afrikaans. As taalorganisasies kon hulle 'n minimale bydrae lewer aangesien die sukses van die Afrikaanse politiek bepalend was vir die ampstaalwording van Afrikaans (vgl. a.w. : 176/9 en 182 e.v.).

By nabetragting ontstaan die vermoede dat die Afrikaner met die ont waking van Alrikanernasionalisme en die gepaardgaande ontdekking van homself, in sy verlede begin delf het en die GRA in 'n groot mate geooridealiseer het. Sodoende is die GRA-manne tot taalhelde verhel' en is die GRA uitgesonder as een van die belangrikste bakens in die geskiedenis van Afrikaans. Dit is insiggewend dat die meeste werke oor die Afrikaanse taalbewegings juis gedurende die jare 1920-1940 verskyn het, sekerlik die glorietydperk van die groei van Afrikanernasionalisme.

\section{GEVOLGTREKKING}

Deur tradisionele uitsprake en opvattinge ten opsigte van die geskiedenis 


\section{Vrae rondom}

van Afrikaans op dié wyse aan die bod te bring, ontwikkel 'n nuwe perspektief op die taal se verlede; 'n perspekt ief wat veel wyer strek as dat die Afrikaanse poging (vrocër en tans) afgestem is op 'n groepie uitverkorenes. Juis in 'n tyd waar die gesprek rondom Afrikaans handel oor die voortbestaansmoontlikhede daarvan, behoort 'n ruimer siening van die taalverlede meer moont likhede te bied vir die positiewe taalhandhawer. Die handhawing van Afrikaans verkry dan 'n opwindende dimensie: om almal wat Afrikaanssprekend is te verenig in 'n handhawingspoging. In 'n hoofartikel van Beeld (18 Junie 1983) word dié uitdaging soos volg gestel: "Ons het inderdaad meer dinge wat ons saambind as wat ons skei, daarom is dit nodig dat almal wat saamhoort rondom Afrikaans versamel word".

\section{BIBLIOGRAFIE}

DE WAAL, J.H.H. 1932. My herinnerings van ons Taalstryd. Nasionale Pers Beperk.

DU PLESSIS, L.T. 1983. 'n Kritiese beskouing van die identifikasie van die Afrikaanse taalbewegıngs en hulle funksies. Ongepubliseerde M.A.-verhandeling. UOVS

- 1983a. Die Afrikaanse Bybelvertalings. Tydskrif vir Letterkunde, 21(3) : $1-13$.

DU TOIT, S.J. 1882. Die Afrikaner Bond: "Eendrag maak mag." D.F. du Toit en Co., Paarl.

- 1909. Geskidenis fan di afrikaanse Taalbeweging. Paarl Drukpers Maatskappy Beperk.

DU TOIT, J.D. 1917. Ds. S.J. du Toit in weg en werk: 'n Periode van Afrikaanse oplewing. Paarl Drukpers Maatschappij Beperkt.

HAUGEN, E. 1981. Language fragmentation in Scandinavia: Revolt of the Minorities. In: Haugen, E.,J.D. McClure en D. Thomson (reds.) : 100-119. HAUGEN, E., J.D. McCLURE en D. THOMSON (reds.). 1981. Minority Languages today. A Selection of Papers read at the First International Conference on Minority Languages held at Glasgow University from 8 to 13 September 1980. Edinburgh University Press.

KANNEMEYER, J.C. 1983. Die Afrikaanse Bewegings. Blokboeke. Academica.

MALHERBE, D.F. s.j. Is Afrikaans 'n dialek? In: Nienaber en Heyl : 66-80. NIENABER, P.J. 1934. Die Geskiedenis van die Afrikaanse Bybelvertaling. Nasionale Pers Beperk. 


\section{L.T. du Plessis}

NIENABER, P.J. en J.A. HEYL. s.j. Pleidooie in belang van Afrikaans. Deel II. Nasionale Boekhandel Beperk.

NIENABER, G.S. en P.J. NIENABER, 1941. Die geskiedenis van die Afrikaanse Beweging. J.L. van Schaik Beperk.

PIENAAR, E.C.. 1943. Die Triomf van Afrikaans. Nasionale Pers Beperk. PIETERSEN, L. 1976. Taalsociologie : Minderheden, Tweetaligheid, Taalachterstand. H.D. Tjeenk Willink.

PONELIS, F.A. 1983. Afrikaanse Klankleer. Balkema (ter perse).

STEYN, J.C. 1980. Tuiste in eie taal: Die behoud en bestaan van Afrikaans. Tafelberg.

VAN RENSBURG, M.C.J. 1981. Twee temas uit Tuiste in eie Taal. Taalfasette, $27(2): 46-54$. 